\title{
O auxílio das ferramentas educomunicativas no ensino de libras para ouvintes
}

\author{
The aid of educommunicative tools in the teaching of libras to listeners
}

\author{
Renata Quinhones Pereira \\ Mestranda em Ensino de Humanidades e Linguagens \\ Universidade Franciscana - UFN \\ Santa Maria, RS, Brasil \\ renata_quinhones@hotmail.com \\ Michele Quinhones Pereira \\ Mestrado em Educação \\ Universidade Franciscana - UFN \\ Santa Maria, RS, Brasil \\ michele_qp@hotmail.com \\ (iD) Taís Steffenello Ghisleni \\ Doutora em Comunicação \\ Universidade Franciscana - UFN \\ Santa Maria, RS, Brasil \\ taisghisleni@yahoo.com.br
}

\begin{abstract}
Resumo: Nesse registro assumimos a concepção atual de inclusão. Independentemente dos conceitos para a palavra inclusão, todos os usos produzem verdades e circulam no nosso cotidiano. Apresentamos as alterações legislativas ocorridas inicialmente no ano de 2005 que determinaram a inserção da disciplina de Língua Brasileira de Sinais (Libras) nos currículos dos cursos de formação de profes sores de todo o Brasil. Nesse sentido, o presente artigo relata a experiência do Playlibras, um projeto desenvolvido pelos alunos da disciplina de Projeto de Extensão e Comunicação Comunitária do Curso de Publicidade e Propaganda da Universidade Franciscana de Santa Maria (UFN), a partir da demanda suscitada pela Professora da disciplina de Libras da instituição, em razão da escassez de materiais na área. O artigo situa-se na interface da educomunicação, no ensino de Libras para ouvintes e apoia-se na perspectiva da pesquisa exploratória.
\end{abstract}

Palavras chave: educomunicação; ensino; inclusão; libras.

Abstract: In this register, we assume the current concept of inclusion. Regardless of the concepts for the word inclusion, all uses produce truths and circulate in our daily lives. We presented the legislative changes that initially occurred in 2005 that determined the insertion of the discipline of Brazilian Sign Language (Libras) in the curricula of teacher training courses throughout Brazil. In this sense, this article reports the experience of Playlibras, a project developed by the students of the Extension and Community Communication Project course of the Advertising and Propaganda Course at the Franciscan University of Santa Maria (UFN), based on the demand raised by the Professor of Libras discipline of the institution, due to the scarcity of materials in the area. The article is located at the interface of educommunication, in the teaching of Libras for listeners and is supported by the perspective of exploratory research.

Key-words: educommunication; teaching; inclusion; pounds.

Cite como

\section{(ABNT NBR 6023:2018)}

PEREIRA, Renata Quinhones; PEREIRA, Michele Quinhones; GHISLENI, Taís Steffenello. O auxílio das ferramentas educomunicativas no ensino de libras para ouvintes. Dialogia, São Paulo, n. 38, p. 1-11, e19605, maio/ago. 2021. Disponível em: https:// doi.org/10.5585/38.2021.19605.

American Psychological Association (APA)

Pereira, R. Q., Pereira, M. Q., \& Ghisleni, T. S. (2021, maio/ago.). O auxílio das ferramentas educomunicativas no ensino de libras para ouvintes. Dialogia, São Paulo, 38, p. 1-11, e19605. https://doi.org/10.5585/38.2021.19605. 


\section{Introdução}

A previsão legislativa, trazida pela Lei n. ${ }^{\circ}$ 10.436, de 2002, oficializou a Língua Brasileira de Sinais (LIBRAS) e a tornou um meio legal de comunicação e expressão dos surdos brasileiros. Ademais, o Decreto n. ${ }^{\circ} 5.626$ de 2005 determinou a inclusão da disciplina de Libras nos currículos dos cursos de formação de professores, de nível médio e superior, em instituições públicas e privadas, inicialmente nos cursos de Pedagogia, Fonoaudiologia e Letras para posterior ampliação progressiva nas demais licenciaturas.

Nesse contexto, verificou-se a necessidade de produzir materiais didáticos que auxiliassem no ensino de Libras para ouvintes, levando em consideração as peculiaridades da língua que é de uma natureza visual-gestual, haja vista que estamos habituados ao método tradicional de ensino da Língua Portuguesa, e demais línguas, que é de uma natureza oral-adutiva. Conforme Gesser (2009) devemos entender que o canal usado pelo surdo para se comunicar tem todas características linguísticas de qualquer língua natural.

A partir desta peculiaridade da Língua de Sinais, as Tecnologias da informação e da Comunicação (TIC) aparecem como ferramentas que podem ser empregadas como aliadas no processo de ensino-aprendizagem em geral, mas especialmente no caso da Libras, a qual é articulada e expressada por sinais, necessitando da visão para sua captação. Nas palavras de Gesser, a comunidade ouvinte necessita entender que "o canal comunicativo diferente (visual-gestual) que o surdo usa para se comunicar não anula a existência de uma língua tão natural, complexa e genuína como é a língua de sinais" (2009, p.21-22).

Pensando nisso, os alunos da disciplina de Projeto de Extensão e Comunicação Comunitária do Curso de Publicidade e Propaganda da Faculdade Franciscana de Santa Maria (UFN) desenvolveram o projeto Playlibras, com o fito de oferecer conteúdos audiovisuais rápidos e práticos sobre Libras, publicados na rede social Instagram.

Assim, no caso em análise, a educomunicação aparece como uma ferramenta de ensino de libras, mas, além disso, como uma forma de sensibilização dos alunos e futuros profissionais em pensar sobre a problemática da inclusão desses sujeitos na sociedade e vislumbrar, quem sabe, uma possibilidade de amenizar as barreiras da comunicação entre surdos e ouvintes. Comunicação também é inclusão.

\section{Legislação e o ensino de libras no Brasil}

Inicialmente, cumpre referir que nas últimas décadas ocorreram avanços significativos na esfera legislativa, bem como no campo da pesquisa e na produção de materiais que incluem as 
pessoas com deficiência na sociedade e na escola. Com o advento da Lei no 10.098 de 2000, instituise no Brasil as normas gerais e critérios básicos para a promoção da acessibilidade das pessoas com deficiência ou com mobilidade reduzida (BRASIL, 2000).

Nesse contexto, o processo de inclusão de surdos nos ambientes escolares tem ocupado destaque, distanciando-se dos cursos e práticas educacionais em que imperava o preconceito e o discurso de normalização. Por muito tempo a utilização da Língua de Sinais foi proibida em sala de aula, sendo os surdos submetidos ao treinamento da fala.

\footnotetext{
A educação da pessoa surda, nos anos sessenta do século XX, acompanhou esse movimento, tendo como bandeiras o reconhecimento da Língua de Sinais, as pesquisas sobre a aquisição da linguagem e a tomada da consciência dos educadores dos resultados poucos satisfatórios dos métodos orais para a aquisição de conhecimento pelos surdos (LIMA; LIMA, 2016, p. 197).
}

Esse grupo de pessoas tem lutado pelo reconhecimento de suas singularidades e de seus direitos ao longo dos anos. No entanto, o reconhecimento da Língua Brasileira de Sinais (Libras) como meio legal de comunicação e expressão e outros recursos de expressão a ela associados somente ocorreu por meio da Lei n 10.436 de 2002, uma decisão de especial relevância para a educação de surdos no Brasil.

A aludida lei conceitua a Libras como sendo:

A forma de comunicação e expressão, em que o sistema linguístico de natureza visualmotora, com estrutura gramatical própria, constitui um sistema linguístico de transmissão de ideias e fatos, oriundos de comunidades de pessoas surdas do Brasil (BRASIL, 2002).

A Libras é considerada como língua da comunidade surda brasileira. Recebe este status porque possui estruturas gramaticais próprias, composta pelos seguintes níveis linguísticos: o fonológico, morfológico, o sintático e o semântico. Nesse sentido, a língua pode ser aprendida por todos aqueles que se interessam pela comunicação com a comunidade surda.

Não obstante, o Decreto n 5.626 de 2005 determinou a inserção da Libras como disciplina curricular obrigatória nos cursos de formação de professores ${ }^{1}$, em nível médio e superior, e nos cursos de Fonoaudiologia, de instituições de ensino, públicas e privadas, do sistema federal de ensino e dos sistemas de ensino dos Estados, do Distrito Federal e dos Municípios (BRASIL, 2005).

\footnotetext{
${ }^{1}$ Conforme o artigo $3^{\circ}, \S 1^{\circ}$, do Decreto ${ }^{\circ} 5.626$ de 2005, todos os cursos de licenciatura, nas diferentes áreas do conhecimento, o curso normal de nível médio, o curso normal superior, o curso de Pedagogia e o curso de Educação Especial são considerados cursos de formação de professores e profissionais da educação para o exercício do magistério (BRASIL, 2005).
} 
Muito se fala sobre a crescente democratização do processo de inclusão, sobretudo no campo educacional. Por conta disso, somos convidados, ou até mesmo, convocados a pensar sobre essas questões nos processos de ensino de Libras para ouvintes.

Diante disso:

\begin{abstract}
O reconhecimento da língua significa o primeiro passo, uma vez que esta precisa ser ensinada e utilizada pela população como forma de garantia de seus direitos de comunicação e, consequentemente, de escolarização. Partindo do princípio de que a participação social, educacional e profissional é um direito de todos e que a Libras é a língua materna dos surdos brasileiros, há a necessidade urgente de torná-la acessível aos profissionais que atuam ou desejam atuar com pessoas surdas, visto que a comunicação é uma condição básica para as interações sociais e para o exercício democrático da cidadania (GODOI; LIMA; ANDRADE, 2016, p. 9).
\end{abstract}

Neste movimento, a Universidade Franciscana de Santa Maria (UFN) tem buscado inserirse no processo de inclusão de forma gradual e permanente desde 2011, quando foi além da exigência legislativa e inseriu a disciplina de LIBRAS em todos os cursos de graduação da instituição.

Sob esse prisma, soma-se, ainda, o fato de que o modelo atual de política brasileiro, trazido pela Lei no 13.146 de 2015, conhecida popularmente como Estatuto da Pessoa com Deficiência, é inclusivo. Tal fato reforça a ideia de que os profissionais devem estar atentos à nova realidade, haja vista que a lei afirmou a autonomia e a capacidade das pessoas com deficiência para exercerem atos da vida civil.

Tendo em vista que a Libras é uma língua gesto-visual e que utiliza a espacialidade para sua reprodução e recepção, faz-se necessário pensar em materiais didáticos que atentem para o fato da tridimensionalidade. Nesse aspecto, o uso da pedagogia visual aparece como um elemento fundamental na efetivação das práticas educacionais de libras, na medida em que pode auxiliar na aprendizagem dos ouvintes em um tripé formado por texto, imagem e vídeo:

(A Pedagogia Visual) É um novo campo de estudos com uma demanda importante da sociedade que pressiona a educação formal a modificar ou criar propostas pedagógicas pautadas na visualidade a fim de reorientar os processos de ensinar e aprender como um todo [...] (CAMPELLO, 2008, p. 10).

Miranda (2013, p. 75) aduz que "saber interpretar e produzir mensagens audiovisuais permite que o indivíduo deixe de ser apenas um receptor e passe a ser um produtor de sentido". Sob esse prisma, a educomunicação aparece como uma ferramenta que possibilita experiências comunicacionais educativas, diferentemente do padrão tradicional que é facilmente encontrado nos espaços e processos educativos da sociedade. Além disso, na experiência que será desvelada a 
seguir, a educomunicação também surge como instrumento de expressão de cidadania, haja vista que torna viável a comunicação entre sujeitos surdos e não surdos.

\section{Considerações metodológicas}

A metodologia utilizada baseia-se na análise documental, bibliográfica e exploratória como suporte para o desenvolvimento do estudo. Nesse sentido, o primeiro momento do trabalho é constituído de documentos legais que compõem o corpus da pesquisa. Tais documentos possibilitam compreender a oficialização da Língua Brasileira de Sinais, a sua obrigatoriedade nos currículos dos cursos de formação de professores e de fonoaudiologia, bem como em que momento a política inclusiva foi instituída no Brasil.

A partir da analítica desenvolvida sobre o primeiro conjunto de documentos, o estudo possui caráter exploratório, a fim de compreender como aconteceu a elaboração e a execução do projeto PlayLibras. O segundo momento da pesquisa relata a experiência do projeto desenvolvido pelos alunos Curso de Publicidade e Propaganda da UFN, em conjunto com a professora de Libras da mesma instituição, idealizadora da proposta educomunicativa. A análise ocorreu a partir do material audiovisual desenvolvido e publicado na rede social Instagram, no período do segundo semestre de 2018.

4 A educomunicação como interface: a experiência de uma ferramenta educomunicativa no ensino de libras para ouvintes

Diante do cenário apresentado e com a obrigatoriedade da oferta da disciplina de Libras nos cursos de graduação, bem como a escassa produção na área de ensino de Libras para ouvintes, verificou-se a emergência de se pensar em materiais didáticos que pudessem ser utilizados, inclusive, à distância para a efetivação do aprendizado da língua de sinais.

Sabendo que os alunos de Libras buscavam materiais de estudo desenvolvidos em outros estados brasileiros e que a língua de sinais, como qualquer outra língua, apresenta variações linguísticas locais, regionais e nacionais, a professora de Libras da Universidade Franciscana (UFN), Michele Quinhones Pereira, buscou junto à disciplina de Projeto de Extensão e Comunicação Comunitária do Curso de Publicidade e Propaganda da instituição o aporte para desenvolver um projeto que aliasse comunicação e o ensino da língua.

Dessa forma, no primeiro semestre de 2018, um grupo de alunos aderiu à ideia e elaborou o briefing do projeto na aludida disciplina. O Playlibras surge com o objetivo de facilitar a comunicação entre sujeitos surdos e ouvintes, bem como de produzir materiais didáticos que possam auxiliar no ensino de Libras não só dos alunos da UFN, mas de toda região. 
Como a ideia era oferecer conteúdos rápidos e práticos sobre Libras, foram produzidos materiais no formato audiovisual para a rede social Instagram e uma identidade visual para o projeto. Conforme o último acesso ao perfil ${ }^{2}$, consoante representado na figura 1 , o Playlibras possui doze publicações e conta com cento e oitenta e cinco seguidores.

Figura 1 - Interface da página PlayLibras na rede social Instagram
(0) Instagram
Q Busca
(2) 0 우

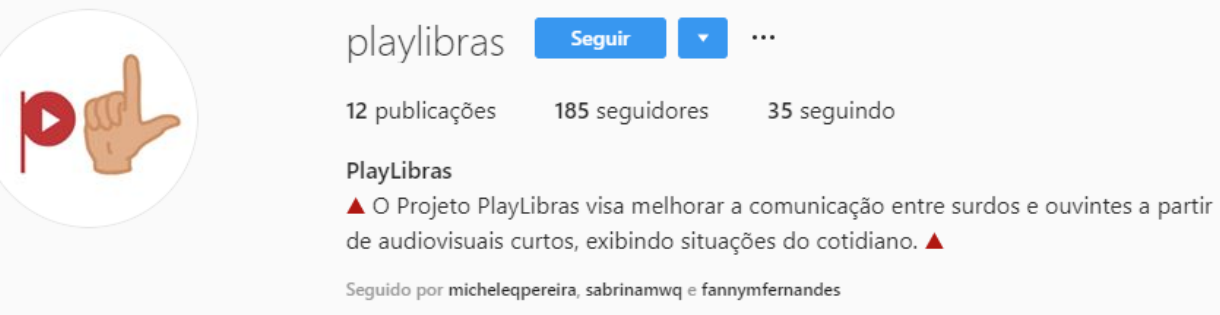

Fonte: Retirada da rede social Instagram.

No primeiro vídeo disponibilizado na página da rede social em referência, os alunos do projeto contextualizam a temática da surdez, assim como explicam a importância do conhecimento da Libras para romper a barreira existente na comunicação entre ouvintes e surdos. Levantam o problema dos entraves enfrentados pelos surdos diariamente ao tentar desempenhar as situações mais recorrentes em nosso cotidiano, haja vista que maior parte da população desconhece a língua.

Para compor os vídeos seguintes, primeiramente, foram realizados os roteiros dos diálogos em Libras. Por conseguinte, os vídeos foram desenvolvidos pelos alunos e a professora da disciplina de Libras nas dependências da universidade. Somente no segundo semestre do ano de 2018 os vídeos foram veiculados na rede social conforme planejado.

Os diálogos estão divididos em três episódios. No episódio 01, o diálogo em Libras contou com a participação de duas professoras de Libras da instituição. O episódio em referência representa uma surda que relata a sua condição e solicita um lanche na cantina, consoante figura 2. Cumpre referir que todos os diálogos em libras disponibilizados contam com legendas.

\footnotetext{
2 Datado em 15 de dezembro de 2019.
} 
Figura 2 - Episódio 01 Cantina
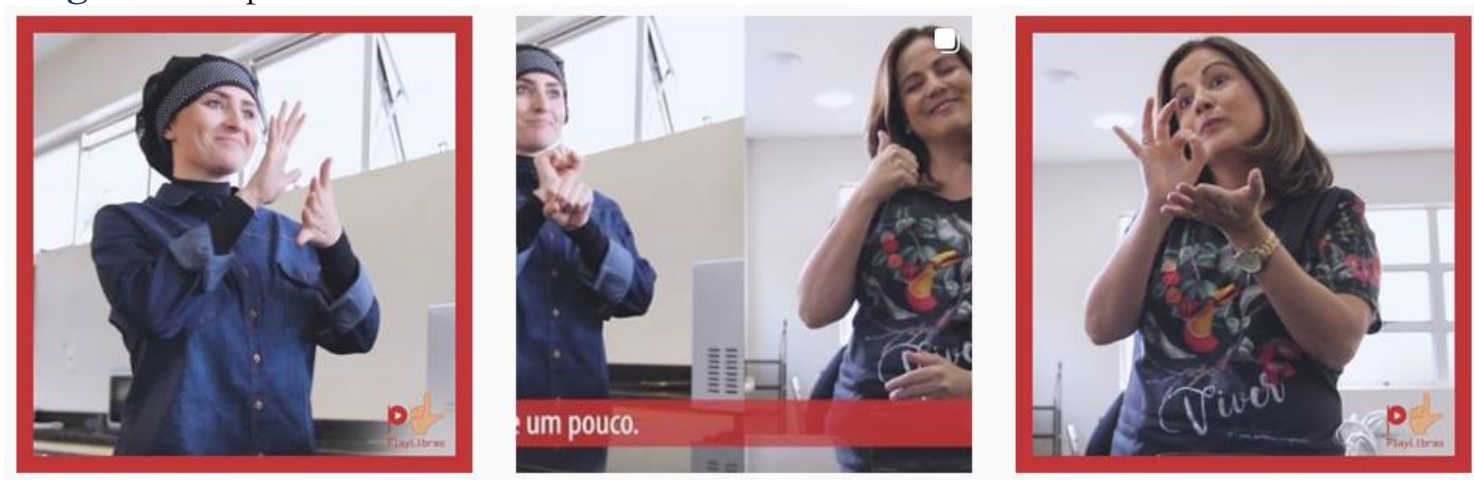

Fonte: Retirada da rede social Instagram.

Disponível em: https://instagram.com/playlibras?utm_medium=copy_link

O episódio 02, por sua vez, conta com a participação da professora de Libras que propôs o projeto e de um aluno, tendo como locação a papelaria que está situada dentro da universidade. No diálogo, o tema central é solicitação de fotocópias de um material, ocasião em que foram exploradas as configurações de mão referentes à quantidade e numerais.

Figura 3 - Episódio 02 xerox
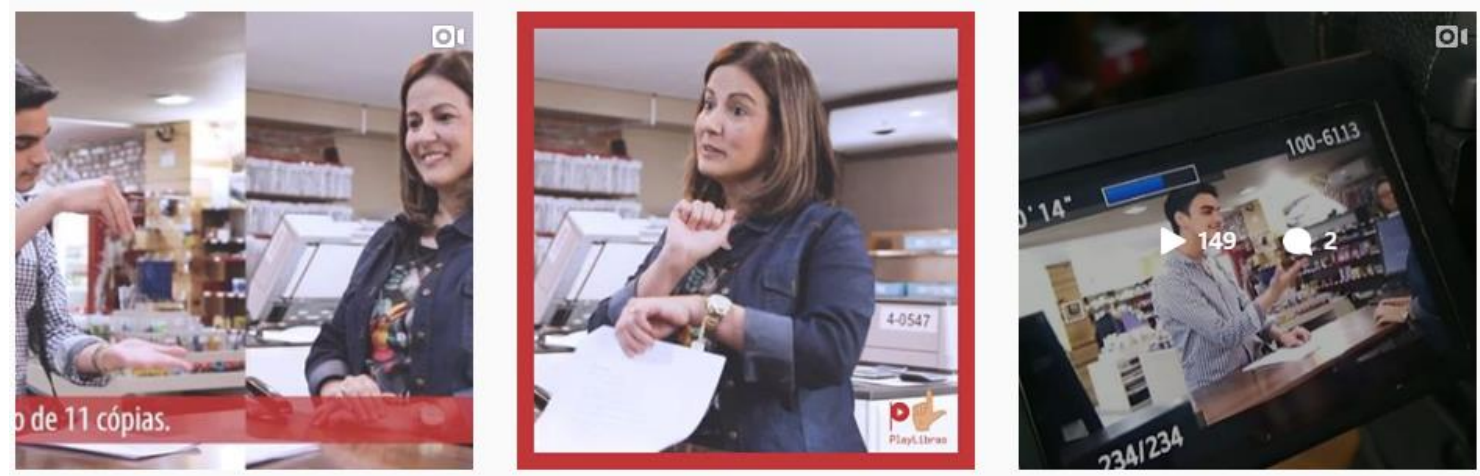

Fonte: Retirada da rede social Instagram.

Disponível em: https://instagram.com/playlibras?utm_medium=copy_link

Já no último episódio postado na página do Playlibras, representado somente pelos alunos do projeto, o diálogo acontece na recepção da instituição. O tema central abordado é a solicitação de informações acerca da sala em que está acontecendo a aula de Libras ministrada pela professora, desse modo o diálogo permite explorar as configurações de mão e o alfabeto manual.

É diante desse panorama, sobre os processos chamados inclusivos, que as tecnologias, bem como os recursos e conteúdos midiáticos disponíveis têm muito a contribuir, na medida em que oferecem ferramentas cada vez mais diversificadas para que os sujeitos participem ativamente do processo de ensino e aprendizagem. 
O conceito educomunicação surgiu no Brasil a partir da década de 1970, ocupando-se dos recursos da informação para a defesa de interesses de grupos. Inicialmente, a educomunicação fora utilizada por professores ligados às questões referentes ao meio ambiente, a partir da perspectiva freiriana da comunicação dialógica, ou seja, baseada na construção de uma educação compartilhada e solidária.

Em entrevista à revista Conhecimento Prático: Geografia, Soares, precursor dos estudos de educomunicação no Brasil, preleciona que:

\begin{abstract}
A Educomunicação vem surgindo desde a década de 1970 para representar todo esforço feito pela sociedade na defesa de causas como as dos indígenas. Ela vem surgindo na América Latina por meio de grupo de pessoas que se reúnem para usar os recursos da informação na defesa de seus interesses a partir da perspectiva freiriana da comunicação dialógica. Então, a educomunicação é praticada, inicialmente, por professores do meio ambiente, por exemplo, que começam a usar tanto a rádio comunitária quanto o vídeo e outras formas de mobilização como teatro, música, vídeos, formação de grupos para a defesa do meio ambiente (NCE, 2009, online).
\end{abstract}

Nesse contexto, segundo Soares, as práticas comunicativas deixam de estar a serviço da indústria cultural e passam ser orientadas pelos objetos educativos a partir da necessidade de incluir sujeitos na sociedade globalizada e midiática capazes de pensar de maneira consciente e crítica.

Conforme Freire (1987, p. 44), "ninguém educa ninguém. Ninguém educa a si mesmo. Os homens se educam entre si, mediatizados pelo mundo". Nesse sentido, a educomunicação propõe uma integração dialógica de dois campos disciplinares, quais sejam: educação e comunicação. Conforme Soares, a educomunicação define-se como um conjunto de ações destinadas a:

um conjunto das ações inerentes ao planejamento, implementação e avaliação de
processos, programas e produtos destinados a criar e a fortalecer ecossistemas
comunicativos em espaços educativos presenciais ou virtuais, assim como a melhorar o
coeficiente comunicativo das ações educativas, incluindo as relacionadas ao uso dos
recursos da informação no processo de aprendizagem. Em outras palavras, a
educomunicação trabalha a partir do conceito de gestão comunicativa. (SOARES, 2000,
p. 24).

No entanto, a educomunicação enquanto ecossistema não emerge espontaneamente num dado ambiente. Precisa ser construída intencionalmente, pois requer práticas inclusivas, democráticas, midiáticas e criativas $\left(\right.$ SOARES $\left.^{1}, 2011\right)$. A comunicação é um direito de todos, prevista na Constituição Federal de 1988. Nessa acepção, verifica-se que o processo educomunicativo está voltado para fazer valer este direito.

Sob este prisma, refere-se que: 
E no caso, as tecnologias vêm facilitar esse trabalho, porque trazem instrumentos e recursos que possibilitam a criação de redes, as chamadas redes sociais que podem se transformar em redes educomunicativas. Educar é da natureza da comunicação, enquanto você se comunica você está se educando e multiplicando esse trabalho. (SOARES, 2015, p. 32).

Assim, verifica-se que a comunicação não é uma simplesmente ferramenta que está à disposição da didática, mas é inerente ao processo educativo, constituindo-se como um processo gerador de conhecimento. Destarte, o projeto Playlibras contempla os pressupostos da educomunicação, quando possibilita que os sujeitos educandos participem como interlocutores do processo de comunicação, de aprendizagem, e como transformadores do ambiente em que vivem.

\section{Considerações finais}

Conforme verificado durante a pesquisa, a emergência de se pensar em conteúdos para o ensino de Libras para ouvintes surgiu a partir da alteração legislativa ocorrida no ano de 2005, a qual incluiu o ensino da língua como disciplina obrigatória nos cursos de formação de professores e além de Fonoaudiologia.

Diante desse cenário, e considerando os elementos discutidos neste estudo exploratório, ficou claro que o Playlibras se trata de uma ferramenta educomunicativa, haja vista que oportunizou o compartilhamento de saberes e técnicas entre os alunos e a professora. O projeto, além de construir um veículo de comunicação entre a comunidade surda e os ouvintes, oportunizou um ambiente de debate acerca da inclusão de pessoas com deficiência na sociedade.

O projeto foi participativo, envolvendo os alunos da disciplina de Projeto de Extensão e Comunicação Comunitária do Curso de Publicidade e Propaganda da UFN, os alunos de outros cursos e que tinham conhecimento de Libras, a própria professora de língua de sinais e uma professora convidada. Constatou-se também o envolvimento da comunidade acadêmica, haja vista que os locais de locação estavam situados dentro da Universidade e foram gentilmente cedidos para a produção dos vídeos.

A educomunicação pode ser realizada de várias formas, podendo ser pontual ou de continuidade. No entanto, no caso em apreço, um dos entraves encontrados pela professora em dar continuidade ao projeto foi justamente o envolvimento de todos os participantes. Com efeito, por se tratar de uma ferramenta educomunicativa, faz-se necessária a participação conjunta entre a professora e alunos.

Ocorre que o fato da disciplina de Projeto de Extensão e Comunicação Comunitária estar situada no sexto semestre do curso, considerando que este é composto por oito semestres, dificulta a permanência dos alunos no Playlibras. Segundo a Professora idealizadora do projeto, o fato de 
estarem na eminência de elaborar o Trabalho Final de Graduação (TGF), acaba fazendo com que os alunos não desenvolvam o projeto nos semestres subsequentes, em razão das demandas que se apresentam no final da graduação.

No entanto, sob o prisma de ferramenta educomunicativa pontual, pode-se afirmar que o Playlibras foi uma ação exitosa, considerando que os conteúdos produzidos são de qualidade e permanecem à disposição da sociedade por meio da rede social instagram. Ademais, no ano de 2018 o Playlibras concorreu ao $12^{\circ}$ Prêmio Universitário de Publicidade promovido pelo Curso de Publicidade e Propaganda da UFN.

Dessa forma, constatou-se que o uso das tecnologias da informação e comunicação aparecem como aliados na construção do conhecimento. A corroborar esta informação, está o fato de que no projeto ora em análise, os alunos e a professora elaboraram os materiais a partir de suas necessidades e interesses, ou seja, tornando-se produtores de conhecimento.

\section{Referências}

BRASIL. Decreto n $n^{\circ}$ 5.626, de 22 de dezembro de 2005. Regulamenta a Lei no 10.436, de 24 de abril de 2002, que dispõe sobre a Língua Brasileira de Sinais - Libras, e o art. 18 da Lei no 10.098, de 19 de dezembro de 2000. Brasília, DF: Diário Oficial da União. Disponível em:

http://www.planalto.gov.br/ccivil_03/leis/2002/110436.htm. Acesso em: 02 dez. 2019.

BRASIL. Lei no 10.098 de 2000, de 19 de dezembro de 2000. Estabelece normas gerais e critérios básicos para a promoção da acessibilidade das pessoas portadoras de deficiência ou com mobilidade reduzida, e dá outras providências. Brasília, DF: Diário Oficial da União. Disponível em: http://www.planalto.gov.br/ccivil_03/leis/110098.htm. Acesso em: 02 dez. 2019.

BRASIL. Lei no 10.436, de 24 de abril de 2002. Dispõe sobre a Língua Brasileira de Sinais - Libras e dá outras providências. Brasília, DF: Diário Oficial da União. Disponível em: http://www.planalto.gov.br/ccivil_03/leis/2002/110436.htm. Acesso em: 05 dez. 2019.

BRASIL. Lei ñ 13.146, de 6 de julho de 2015. Estatuto da Pessoa com Deficiência. Brasília, DF: Diário Oficial da União. Disponível em: http://www.planalto.gov.br/ccivil_03/_ato20152018/2015/lei/113146.htm. Acesso em: 29 nov. 2019.

CAMPELLO, Ana Regina de Souza. Pedagogia visual na educaşão dos surdos-mudos. 2008. Tese (Doutorado em Educação). Universidade Federal de Santa Catarina, Florianópolis, 2008. Disponível em: http://www.fkb.br/arquivos/nbr.pdf. Acesso em: 10 dez. 2019.

FREIRE, Paulo. Pedagogia do oprimido. 17. ed. Rio de Janeiro: Paz e Terra, 1987.

GESSER, Audrei. Libras? Que língua é essa?: crenças e preconceitos em torno da língua de sinais de da realidade surda. São Paulo: Parábola, 2009. 
GODOI, Eliamar; LIMA, Marisa Dias; ANDRADE, Valdete A. Borges (org.). Lingua Brasileira de Sinais - LIBRAS: a formação continuada de professores. Uberlândia: EDUFU, 2016. E-book. Disponível em: http:/ /www.edufu.ufu.br/sites/edufu.ufu.br/files/ebook_lingua_brasileira_de_sinais_v3_2016_0.pdf. Acesso em: 28 nov. 2019.

INSTAGRAM. Playlibras. Disponível em: https://www.instagram.com/playlibras/?hl=pt-br. Acesso em: 20 nov. 2019.

MIRANDA, Fabiana Maria Whonrath. Cinema e produção de vídeo na escola: da prática à análise de questões pedagógicas sobre o ensino da linguagem audiovisual. In: PAVANI, Cecília; PARENTE, Cristiane; ORMANEZE, Fabiano. (org.). Educomunicação, redes sociais e interatividade. 1. ed. Campinas: Leitura Crítica, 2013. p. 75-94.

NÚCLEO DE COMUNICAÇÃO E EDUCAÇÃO DA UNIVERSIDADE DE SÃO PAULO. São Paulo: NCEUSP, 2009. Disponível em: http://www.usp.br/nce/?wcp=/novidades/informe,7,1159. Acesso em: 6 dez. 2019.

LIMA, Marisa Dia; LIMA, Marcia Dias. Percurso histórico da educação de surdos no mundo e no Brasil: modelos educacionais. In: GODOI, Eliamar; LIMA, Marisa Dias; ANDRADE, Valdete A. Borges (org.). Lingua Brasileira de Sinais - LIBRAS: a formaçã $z o$ continuada de professores. Uberlândia: EDUFU, 2016, p. 197-255. E-book. Disponível em:

http://www.edufu.ufu.br/sites/edufu.ufu.br/files/ebook_lingua_brasileira_de_sinais_v3_2016_0.pdf. Acesso em: 28 nov. 2019.

SOARES, Ismar de Oliveira. Educomunicação: um campo de mediações. Comunicação \& Educaşão, n.19, p. 12-24, 30 dez. 2000.

SOARES, Ismar de Oliveira. Educomunicação. O conceito, o profissional, a aplicação. São Paulo: Paulinas. 2011.

SOARES ${ }^{1}$, Ismar. Educomunicação: um campo de mediações. In: CITELLI, Adilson; COSTA, Maria Cristina Castilho (org.). Educomunicação - construindo uma nova área de conhecimento. São Paulo: Paulinas, 2011, p. 13-30.

SOARES, I. de O. Educomunicação e Educação Midiática: vertentes históricas de aproximação entre comunicação e educação. Comunicaşão \& Educação, [S. l.], v. 19, n. 2, p. 15-26, 2014. Disponível em: https://www.revistas.usp.br/comueduc/article/view/72037. Acesso em: 23 jul. 2021.

SOARES, Ismar [entrevista cedida a] Vera Lucia Spacil Raddatz. In: LAGO, Claudia; VIANA, Claudemir Edson (org.). Educomunicaşão: caminhos da sociedade midiática pelos direitos humanos. São Paulo: ABPEducom/NCE-USP/Universidade Anhembi Morumbi, 2015, p. 28-35. 